\title{
Comunicación
}

\section{DETERMINACIÓN DE RESIDUOS DE ANTIBIÓTICOS BETALACTÁMICOS MEDIANTE UN ENSAYO INMUNOENZIMÁTICO EN LECHE DE VACAS TRATADAS CONTRA MASTITIS}

\author{
Determination of Betalactamic Antibiotic Residues Using an \\ Immunoenzymatic Assay in Milk of Cows Treated Against Mastitis
}

Paúl Salas Z. ${ }^{1}$, Sonia Calle E. ${ }^{1,4}$, Néstor Falcón T. ${ }^{3}$, Chris Pinto J. ${ }^{1}$, Juan Espinoza B. ${ }^{2}$

\section{Resumen}

El presente estudio tuvo por objetivo determinar la frecuencia de residuos de antibióticos en leche de vacas luego del periodo de descarte (tres días) de leche por tratamiento contra la mastitis con antibióticos betalactámicos. Muestras de leche de 60 vacas se analizaron mediante la prueba inmunoenzimática SNAP (Betalactam), que indica la presencia de antibióticos betalactámicos en leche. El 45.0\% (27/60) resultó positivo a residuos de antibióticos. En relación al tipo de antibiótico utilizado, el 56.0\% (14/25), $26.7 \%$ (4/15) y 45.0\% (9/20) de las muestras de animales tratados con la asociación penicilina y estreptomicina, kanamicina y penicilina, y amoxicilina y ácido clavulónico, respectivamente, fue positiva a la prueba. Asimismo, el 50.0\% (14/28) de los animales tratados por vía intramuscular y $40.6 \%$ (13/32) por vía intramamaria fueron positivos; y el $46.7 \%(7 / 15), 57.1 \%(12 / 21)$ y $33.3 \%$ (8/24) de las vacas de baja, media y alta producción, respectivamente, fue positiva a la prueba; aunque sin que hubiera una asociación estadística entre el tipo de antibiótico, vía de administración, y nivel de producción con la presencia de residuos de antibióticos.

Palabras clave: Residuos de antibióticos, leche, vacas, mastitis

\section{Abstract}

The aim of the study was to determine the frequency of antibiotic residues in milk from cows that had clinical mastitis and returned to production after completion of the 3 day period of discarded milk post treatment. Milk samples were collected from 60 cows that received treatment for mastitis with betalactamic antibiotics. Samples were analyzed by the inmunoenzimatic test SNAP (Betalactam), which indicates presence of betalactamic

\footnotetext{
${ }^{1}$ Laboratorio de Microbiología y Parasitología Veterinaria, ${ }^{2}$ Laboratorio de Farmacología y Toxicología Veterinaria, Facultad de Medicina Veterinaria, Universidad Nacional Mayor de San Marcos, Lima

${ }^{3}$ Facultad de Veterinaria y Zootecnia, Universidad Peruana Cayetano Heredia, Lima

${ }^{4}$ E-mail: calleson@gmail.com
} 
antibiotics residues in milk. Results showed that $45.0 \%(27 / 60)$ were positive to betalactamic antibiotics residues. Also, 56.0\% (14/25), 26.7\% (4/15), and 45\% (9/20) of samples from animals treated with penicillin and streptomycin, kanamycin and penicillin, and amoxicillin and clavulanic acid respectively had antibiotic residues. In addition, $50.0 \%(14 / 28)$ of the animals treated by the intramuscular route and $40.6 \%(13 / 32)$ by the intramammary route were positive; whereas $46.7 \%$ (7/15), $57.1 \%(12 / 21)$, and $33.3 \%(8 / 24)$ of cows with low, medium, and high production cows, respectively, were positive to the test. However, no statistical association between type of antibiotic used, via of administration and level of production with presence of antibiotic residues was found.

Key words: Antibiotic residues, betalactamic, milk, cow, mastitis

\section{INTRODUCCIÓN}

El consumo de leche contaminada con residuos de antibióticos es un problema de salud pública emergente a nivel mundial, de ahí la importancia del control de la presencia de residuos de antibióticos en los alimentos para evitar la aparición de resistencia a estos antibióticos en el ser humano.

La leche constituye una vía natural de eliminación para los antibióticos y sus metabolitos, y la cantidad presente depende de la dosis y vía de aplicación, nivel de producción de leche, tipo y grado de afección mamaria y tiempo que media entre el tratamiento y el ordeño. Por otro lado, la administración oral, intramuscular o intravenosa tiene menos importancia, desde el punto de vista de higiene de leche, que la aplicación por vía intramamaria. Los antibióticos de aplicación intramamaria son de fácil aplicación y generalmente más económicos, por lo que su uso es preferido en explotaciones lecheras (Magariños, 2000).

La aparición de residuos de medicamentos en la leche se debe generalmente a que no se respetan tiempos de espera o se usan dosis excesivas (Pérez et al., 2005). Entre los residuos más comunes en la leche se encuentran las sulfonamidas y nitrofuranos, dado que se usan para el con- trol de mastitis (inflamación de la ubre) y los plaguicidas órgano fosforados que se aplican como ectoparasiticidas para el control de moscas y garrapatas (Pérez et al., 2005). Los antibióticos pueden influir en la inducción de resistencia microbiana, desórdenes de la flora intestinal y reacciones alérgicas; y algunos como la sulfametazina y la furazolidona se consideran carcinogénicos (Honkanen y Reybroeck, 1997).

En el Perú no existe una legislación que norme el límite máximo permisible de residuos de antibióticos en leche; sin embargo, se utiliza como referencia para el intercambio internacional de alimentos, normas internacionales como el Codex Alimentarius (el cual regula los niveles máximos permisibles de residuos de antibióticos en leche) por el Acuerdo de Medidas Sanitarias y Fitosanitarias de la Organización Mundial del Comercio, organización que el país está adscrito.

Las técnicas biológicas para detectar sustancias antimicrobianas utilizan microorganismos tales como Sarcina lutea, Bacillus stearothermophilus, Bacillus subtillis y Bacillus megaterium (Moreno, 2003). Otra prueba más reciente es un ensayo inmunoenzimático de competición, que detecta cuantitativamente la cantidad de residuo de antibiótico presente en la leche. Esta es una prueba rápida y eficaz con un nivel de 
sensibilidad del 95\%, y que es usada actualmente como método «screening» en las normas sobre leche pasteurizada de la NCIMS de los EEUU (NCIMS, 2004).

En el país se han realizado algunas investigaciones sobre la presencia de residuos de antibióticos en leche de expendio (Gutiérrez, 1962; Llanos, 2002; Ortiz et al., 2008). El presente estudio tuvo por objetivo determinar residuos de antibióticos en leche de vacas con mastitis clínica tratada con antibióticos betalactámicos.

\section{MATERIALES Y Métodos}

Se tomaron muestras de leche $(10 \mathrm{ml})$ de 60 vacas tratadas contra mastitis clínica con antibióticos betalactámicos entre los meses de agosto de 2005 y abril de 2006. Las muestras fueron recogidas en siete establos de la cuenca lechera de Lima, con un consentimiento firmado de mantener en el anonimato la identidad de los establecimientos muestreados. En estos establos, las vacas eran alimentadas con concentrado y chala, y se empleó ordeño mecánico con una frecuencia de dos veces por día.

Las muestras se tomaron en el primer ordeño después de tres días del retiro del tratamiento. Asimismo, se tomaron muestras controles (una por establo muestreado) correspondiente a leche de vacas que no recibieron tratamiento antibacteriano en al menos un mes previo al estudio. Paralelamente, se registró la producción de leche, tipo de antibiótico y vía de administración utilizada. Las muestras se transportaron a $10^{\circ} \mathrm{C}$ y se procesaron en el Laboratorio de Bacteriología de la Facultad de Medicina Veterinaria, Universidad Nacional Mayor de San Marcos, Lima.

Las muestras de leche se analizaron mediante el kit diagnóstico SNAP Betalactam $^{\circledast}$ (IDEXX Laboratories, Inc) el mismo día de su recolección. La prueba es de tipo inmunoenzimático competitivo que detecta la presencia de residuos de antibióticos de la familia de los betalactámicos, incluyendo penicilina G, amoxicilina, ampicilina, ceftiofur y cefapirina. Tiene un grado de sensibilidad y especificidad del $100 \%$, ya que los niveles mínimos que detecta coinciden con los límites máximos de residuos que pueden aceptarse en la leche según normas europeas.

Los datos se analizaron teniendo en cuenta el criterio de prevalencia límite, donde al menos una muestra positiva asegura que la frecuencia de leche con residuos de antibióticos betalactámicos se encuentra en el nivel de prevalencia límite del 5\%. Además, se determinó la frecuencia de muestras positivas de acuerdo al tipo de antibiótico y vía de administración (intramamaria o intramuscular), así como la producción de leche (alta, media y baja; aproximadamente 25 , 16 y 13 L/día, respectivamente). La asociación estadística entre cada variable del estudio con la presencia de residuos de antibióticos en la muestra se evaluó con la prueba de Chi cuadrado, utilizando el programa estadístico SPSS v. 15 para Windows.

\section{Resultados y Discusión}

El 45\% (27/60) de las muestras resultaron positivas a la prueba de betalactámicos; es decir, muestras de leche con residuos de antibióticos después de tres días de terminado el tratamiento contra mastitis, que es el momento que la leche de estos animales ingresa al tanque de producción y es destinada al consumo humano o a la preparación de subproductos lácteos. Estos niveles son superiores a los límites máximos permisibles de residuos de antibióticos betalactámicos en leche según las normas europeas (FAO/ OMS, 2007).

El 56.0\% (14/25) de las muestras de animales tratados con una asociación de penicilina y estreptomicina resultaron positivas. Asimismo, el 26.7\% (4/15) de las vacas tratadas con la asociación kanamicina y penici- 
lina y $45 \%(9 / 20)$ de los tratados con la asociación amoxicilina y ácido clavulónico. Por otro lado, el 50.0\% (14/28) de animales tratados por vía intramuscular y el $40.6 \%$ (13/ 32) de animales tratados por vía intramamaria presentaron residuos de antibióticos en leche, diferencias que no fueron estadísticamente significativas. Asimismo, tampoco se encontraron diferencias estadísticas en la frecuencia de animales positivos con producción de leche baja $(46.7 \%)$, media $(57.1 \%)$ y alta $(33.3 \%)$.

En un estudio realizado en Cajamarca (Llanos, 2002), el 20\% de muestras dieron positivas a residuos de antibióticos, pero estas muestras provenían de mercados, tiendas y fundos donde los residuos están diluidos, dado que la leche de vacas positivas se mezcla con leche de vacas negativas. Por otro lado, en ese estudio se emplearon pruebas microbiológicas en placa, que son menos sensibles para detectar dichos residuos. En el presente estudio, las muestras procedieron de vacas previamente tratadas con antibióticos, empleándose un método de detección más sensible y específico.

Es importante resaltar que la detección de antibióticos se realizó de manera individual con el fin de determinar si el tiempo de espera utilizado en el país entre el fin del tratamiento con antibióticos y la incorporación de la leche en el tanque de producción es el adecuado. Estudios llevados a cabo en México con esta prueba demostraron que la persistencia de residuos de antibióticos se prolonga hasta seis días después de terminado el tratamiento (Ocampo y Rodríguez, 2001). Es probable que para las condiciones de Lima, debido al tipo y forma de empleo de antibióticos, se requiera implementar un mayor tiempo de retiro de la leche.

\section{Literatura Citada}

\section{1. [FAO/OMS] Programa Conjunto FAO/OMS sobre Normas Alimen- tarias. Grupo de Acción Interguber-}

namental Especial del Codex. 2007. Actividades de la FAO, la OIE y la OMS sobre la contención de la resistencia a los antimicrobianos causada por el uso no humano de agentes antimicrobianos. Italia: FAO/OMS. 7 p.

2. Gutiérrez RJM 1962. Detección de antibióticos en la leche de consumo de Lima, Callao y Balnearios. Tesis de Bachiller en Medicina Veterinaria. Lima: Universidad Nacional Mayor de San Marcos. 60 p.

3. Honkanen BT, Reybroeck W. 1997. Antimicrobials. In: Monograph on residues and contaminants in milk and milk products. Brussels: IDF. p 26-33.

4. Llanos CG. 2002. Determinación de residuos de antibióticos en la leche fresca queconsume la población de Cajamarca. Rev Amazónica Inv Alimentaria 2(2): 35-43.

5. Magariños H. 2000. Producción higiénica de la leche cruda. Guatemala: Producción y Servicios Incorporados. 95 p.

6. Moreno GB. 2003. Higiene e inspección de carnes. Vol II. España: Días de Santos. $624 \mathrm{p}$.

7. [NCIMS] National Conference on Interstate Milk Shipments. 2004. Milk safety requirements for raw bovine milk. [Internet]. Available in: http:// www.fda.gov/Food/FoodSafety/ Product-SpecificInformation/MilkSafety/ Coded Memoranda/MemorandaofInformation/ucm075157.htm

8. Ocampo L, Rodríguez R. 2001. Determinación del tiempo de retiro de la ordeña de vacas tratadas con preparados intramamarios de sulfametoxazoltrimetropim y sulfadiazina-trimetropim. En: XXV Congreso Nacional de Buiatría. Veracruz, México.

9. Ortiz C, Vera R, Cayro J. 2008. Frecuencia de $\beta$-lactámicos y tetraciclinas en leche fresca en la cuenca de Arequipa. Rev Inv Vet, Perú 19: 140-143.

10. Pérez A, Vega y León S, Gutiérrez, $R$, Díaz G, Monroy C, Coronado M. 2005 Residuos de medicamentos veterinarios y plaguicidas organofosforados en leche y derivados. Carnilac 70: 2-3. 